\title{
Influência das transformações urbanas no conforto acústico: estudo-piloto da cidade universitária da UFRJ
}

\author{
Urban transformation influence over the acoustic comfort: pilot study from the \\ Federal University of Rio de Janeiro Campus
}

Flavia Benevides Magioli, Julio Cesar Boscher Torres

Universidade Federal do Rio de Janeiro (UFRJ), Rio de Janeiro, RJ, Brasil

\section{Resumo}

O objetivo deste trabalho é apresentar uma metodologia para análise da influência das transformações urbanas no conforto acústico de um espaço urbano. Esta avaliação é baseada em um estudo-piloto, utilizando como objeto de análise a Cidade Universitária da Universidade Federal do Rio de Janeiro, na qual diversas transformações urbanas vêm ocorrendo ao longo dos anos, muitas destas definidas pelo Plano Diretor da UFRJ para o ano de 2020. A avaliação do impacto das transformações foi realizada através da comparação dos mapas de ruído produzidos pelas diversas configurações urbanas, principalmente as viárias e morfológicas das edificações. A validação dos mapas foi realizada através da medição dos níveis de pressão sonora nos pontos de interesse. Os mapas foram gerados utilizando dados de contagens veiculares e levantamento da tipologia física local. Os resultados da análise dos mapas, em função das transformações urbanas, permitiram constatar que os níveis de ruído na área estão acima dos recomendados legalmente e identificar as principais causas dessa elevação de ruído. Dessa forma, foi possível realizar uma análise crítica das transformações ao longo do tempo e da configuração espacial atual, para propor medidas mitigadoras da poluição sonora e obter um quadro de maior conforto acústico na Ilha do Fundão, sede da Cidade Universitária da UFRJ.

Palavras-chave: Ruído ambiental e urbano. Planejamento urbano. Poluição sonora.

\section{Abstract}

This work aims to present a methodology to analyze the influence of the urban transformation in the acoustic comfort for an urban space. This evaluation is based on a pilot study, using the campus of the Federal University of Rio de Janeiro (UFRJ) as object of analysis. Several urban transformations took place along the years, many of them proposed by the Master Plan of UFRJ for 2020. The noise impact evaluation due to the transformations was performed through noise map comparison of several urban configurations, mainly by traffic flow and buildings morphology. The noise map validation was performed by noise level measurements at points of special interest. The maps were generated using vehicular data counting and typology survey. The maps analysis as function of the urban transformations shown that the noise levels are higher than the stated by the environmental

FBM é arquiteta, bacharel, e-mail: flaviamagioli@poli.ufrj.br JCBT é engenheiro eletrônico, D.Sc., e-mail: julio@poli.ufrj.br 
standards, and allowed to identify the main causes of such noise increase. Therefore, it was able to critically analyze the urban transformations along the time and the actual spatial configuration in order to propose actions to reduce the noise pollution and improve the hearing comfort at the UFRJ campus.

Keywords: Urban and environmental noise. Urban planning. Noise pollution.

\section{Introdução}

Atualmente, o conceito de Smart Cities é cada vez mais utilizado para a gestão de sistemas complexos, tratando a cidade como um laboratório cívico transformador das relações entre comunidade e serviços urbanos. 0 resgate desse conceito surge pela necessidade de adoção de tecnologias e estratégias sustentáveis de mitigação e adaptação às mudanças climáticas, após o acordo legalmente ratificado pelo Protocolo de Kyoto, para redução do efeito estufa. Entre as diversas organizações que vêm desempenhando um papel importante neste empreendimento, as universidades têm um papel único e insubstituível, pois são responsáveis pela formação de futuros líderes em diversos setores e pela educação dos futuros profissionais, consumidores e contribuintes. Portanto, a educação universitária e a vivência no Campus teriam um longo alcance de influência na sociedade, além de influir significativamente nos avanços da ciência e tecnologia, e no desenvolvimento econômico das cidades (König, 2013).

A cidade inteligente pode ainda transcender a sua funcionalidade inicial de gestão de serviços e infraestrutura, através de uma gestão territorial que agregue os temas sociais, econômicos e ambientais. Mais do que funcionalidade em automação e controle, o conceito de Smart Cities representa a cidadania e a sustentabilidade. Quando aplicamos este conceito ao âmbito de uma Cidade Universitária, suscitamos o Smart Campus (Lima et al., 2015).

A Cidade Universitária da UFRJ pode ser considerada um Smart Campus, na medida em que funciona como um laboratório de cidades, que possui as diversas atividades da sociedade - escola, hospital, creche, serviços, comércio, empresas, área residencial, terminais de ônibus e integração com o metrô.

Nesse contexto de ações integradas, a poluição ambiental é um dos elementos a serem considerados na transformação dos espaços urbanos. A poluição sonora é, atualmente, um dos principais problemas ambientais dos grandes centros urbanos e a causa de alterações físicas e psicológicas nos seres humanos.
Um dos motivos de a poluição sonora ser a terceira fonte de poluição mundial é o fato de se negligenciar a influência do som no bem-estar do ser humano (Raimbault et al., 2003; Brasil, 2006).

0 ruído excessivo compromete a qualidade de vida do indivíduo exposto, já que pode ser prejudicial ao bem-estar físico, emocional, mental e social, podendo ocorrer reações no organismo, tais como: alterações na pressão sanguínea e na frequência cardíaca; tensão muscular; liberação de hormônios; falta de atenção; distúrbios do sono; falta de concentração, e irritabilidade, entre outros. A audição pode ser afetada pelos ruídos através da mudança temporária no limiar (fadiga auditiva), através de trauma acústico (perda auditiva súbita) ou pela perda auditiva induzida por ruído - PAIR (FIOCRUZ, 2015; Ribas et al., 2010).

A reação das pessoas ao ruído não depende apenas das características físicas do som, mas também das características auditivas individuais, dentre as quais devem ser considerados aspectos físicos e subjetivos, tais como pré-conceitos sobre a percepção do ruído e a influência da própria personalidade na sensibilidade ao ruído (Zimmer \& Ellermeier, 1999; Moreira \& Bryan, 1972).

O ruído de trânsito se destaca como fonte de poluição sonora nos centros urbanos, sendo os veículos automotores a principal fonte de ruído (Huang et al., 2009). Apesar de a Lei Brasileira de Crimes Ambientais n. $9.605 / 98$ abordar em seu artigo 54 a poluição sonora como crime, constatam-se níveis de ruído acima dos valores recomendados nos grandes centros urbanos (Brasil, 1998).

0 principal Campus da Universidade Federal do Rio de Janeiro (UFRJ), a Cidade Universitária, está situado na Ilha do Fundão, na margem oeste da Baía de Guanabara, com área total de $4.667 .943 \mathrm{~m}^{2}$. Na Ilha, está concentrada a maioria das unidades acadêmicas e administrativas da UFRJ, além de importantes empresas e centros de pesquisa, abrigando ainda áreas residenciais e hospitalares, o que a caracteriza como uma área de uso misto (acadêmico, industrial, hospitalar, comercial e residencial). 
O Plano Diretor da Universidade (PD-UFRJ-2020) prevê o aumento das vagas oferecidas a alunos e busca ainda reverter distorções que foram se acumulando desde a sua criação, quando inspirada em concepções modernistas, marcadamente rodoviaristas e funcionalistas, gerando espaços desintegrados. Entre suas diretrizes, que norteiam o desenvolvimento territorial da Cidade Universitária, estão: Mobilidade, Acessibilidade à Cidade Universitária, Integração com a cidade - usos compartilhados, Humanização dos espaços, Responsabilidade ambiental e energética, e Aumento de densidades (UFRJ, 2011).

Segundo o PD-UFRJ-2020, as principais vias (eixos) de conexão com a cidade do Rio de Janeiro não são suficientes diante do crescente fluxo de veículos, causando engarrafamentos quotidianos e custos ambientais, financeiros e psicossociais. Portanto, existe a necessidade de criar combinações intermodais que priorizem o transporte metro-ferroviário e hidroviário, de forma a mitigar a atual situação, que é predominantemente rodoviária.

A partir dessas diretrizes, algumas ações e iniciativas contidas no PD-UFRJ-2020 já se tornaram realidade: novas edificações já foram construídas e outras estão sendo projetadas para atender às demandas requeridas pelas expansões acadêmicas. Uma destas intervenções realizadas é a Ponte do Saber, a primeira ponte estaiada do Rio de Janeiro, que liga a Cidade Universitária ao continente, tendo sido inaugurada em 17 de fevereiro de 2012.

A Ponte do Saber tornou-se um novo fator de geração de tráfego, pois proporcionou um trajeto alternativo das viagens no sentido Baixada $\rightarrow$ Centro, para os usuários da Linha Vermelha - importante via expressa - em períodos de congestionamento.

Esta e outras alterações da configuração espacial nas principais rodovias da Cidade Universitária geram agravantes relacionados ao ruído urbano. Os veículos automotores utilizam as principais rodovias da Cidade Universitária como rota alternativa de uma das principais vias expressas da cidade do Rio de Janeiro, tanto no sentido Baixada-Centro quanto no sentido Centro-Baixada. Este fluxo excedente de veículos é proveniente das vias expressas Presidente João Goulart (Linha Vermelha) e Avenida Governador Carlos Lacerda (Linha Amarela), nos períodos de engarrafamentos. 0 aumento do volume de veículos nas vias afeta negativamente a acústica do ambiente, causando transtornos aos diversos usuários deste território.
As intervenções viárias que vêm ocorrendo ao longo dos anos, sendo algumas direcionadas pelo Plano Diretor da Universidade, também geram desconforto acústico aos usuários deste espaço urbano de uso diversificado e misto. Objetivando minimizar este desconforto, os níveis de ruído produzidos no local são analisados, através da elaboração de mapas de ruído e de medições nos principais trechos da Cidade Universitária, a fim de contribuir para a construção de um melhor quadro de conforto acústico.

Portanto, este trabalho se configura em estudo-piloto de ações integradas da engenharia urbana, congregando conforto ambiental acústico a ações urbanísticas e de engenharias setoriais (transporte, uso do solo, etc.). Aponta para a elaboração de diagnósticos e prospecção de cenários, por meio da análise acústica baseada em informações referentes às atividades universitárias e sua infraestrutura.

\section{Impacto da configuração viária}

Ao longo do tempo, diversas alterações viárias foram realizadas na Cidade Universitária, gerando desvios no fluxo de veículos, que passaram a utilizar as vias locais como rota alternativa à Linha Vermelha — via expressa da cidade. Este aumento significativo da quantidade de veículos impacta diretamente na poluição sonora, causando transtornos aos usuários. As principais rotas, dentro do Campus, utilizadas como alterativas às vias expressas são apresentadas nas Figuras 1, 2 e 3.

Durante a gestão do Prefeito Conde (de 1997 a 2000), no Rio de Janeiro, foi criada a conexão (alça) entre duas vias expressas da cidade, a Linha Amarela e a Linha Vermelha, próxima ao ponto 3 da Figura 1. Essa alteração possibilitou uma nova alternativa de conexão entre as Linhas Vermelha e Amarela por dentro do Campus, para os veículos provenientes da Baixada. Surgiu também uma conexão no sentido contrário, porém esta não tem impacto significativo, pois o tráfego se desloca diretamente para a Linha Amarela. Este novo fator gerador de tráfego impactou nas principais avenidas locais, desde a Prefeitura Universitária (ponto 10) até o Centro de Ciências Matemáticas e da Natureza (CCMN), com o aumento significativo do fluxo de veículos neste trecho.

A Ponte do Saber foi inaugurada em fevereiro de 2012 e criou mais uma alternativa para o fluxo 


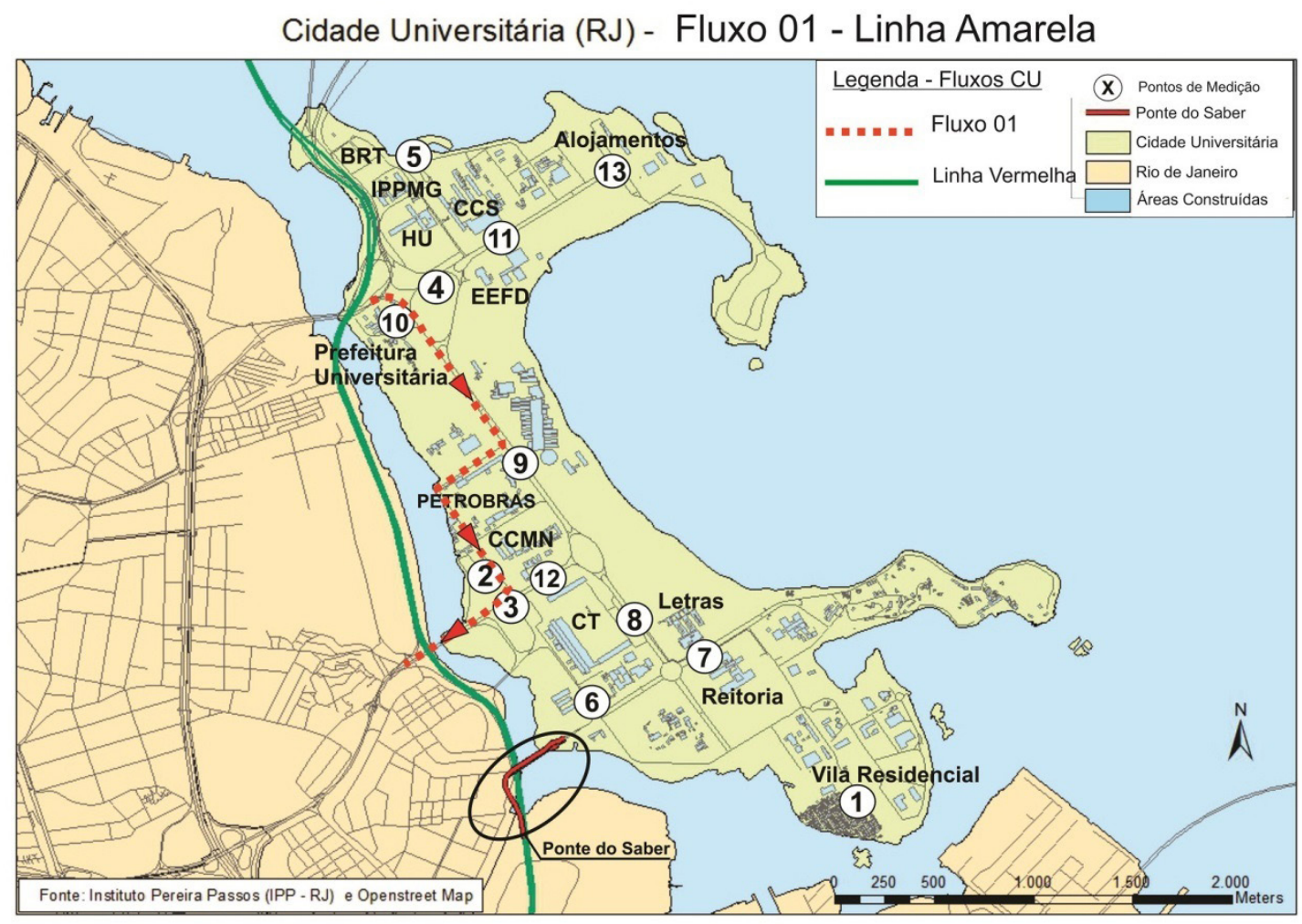

Figura 1 - Fluxo 1 (Linha Amarela), Cidade Universitária (RJ)

Fonte: Elaboracã̃o dos autores (2016).

\section{Cidade Universitária (RJ) - Fluxo 02 - Baixada-Centro}

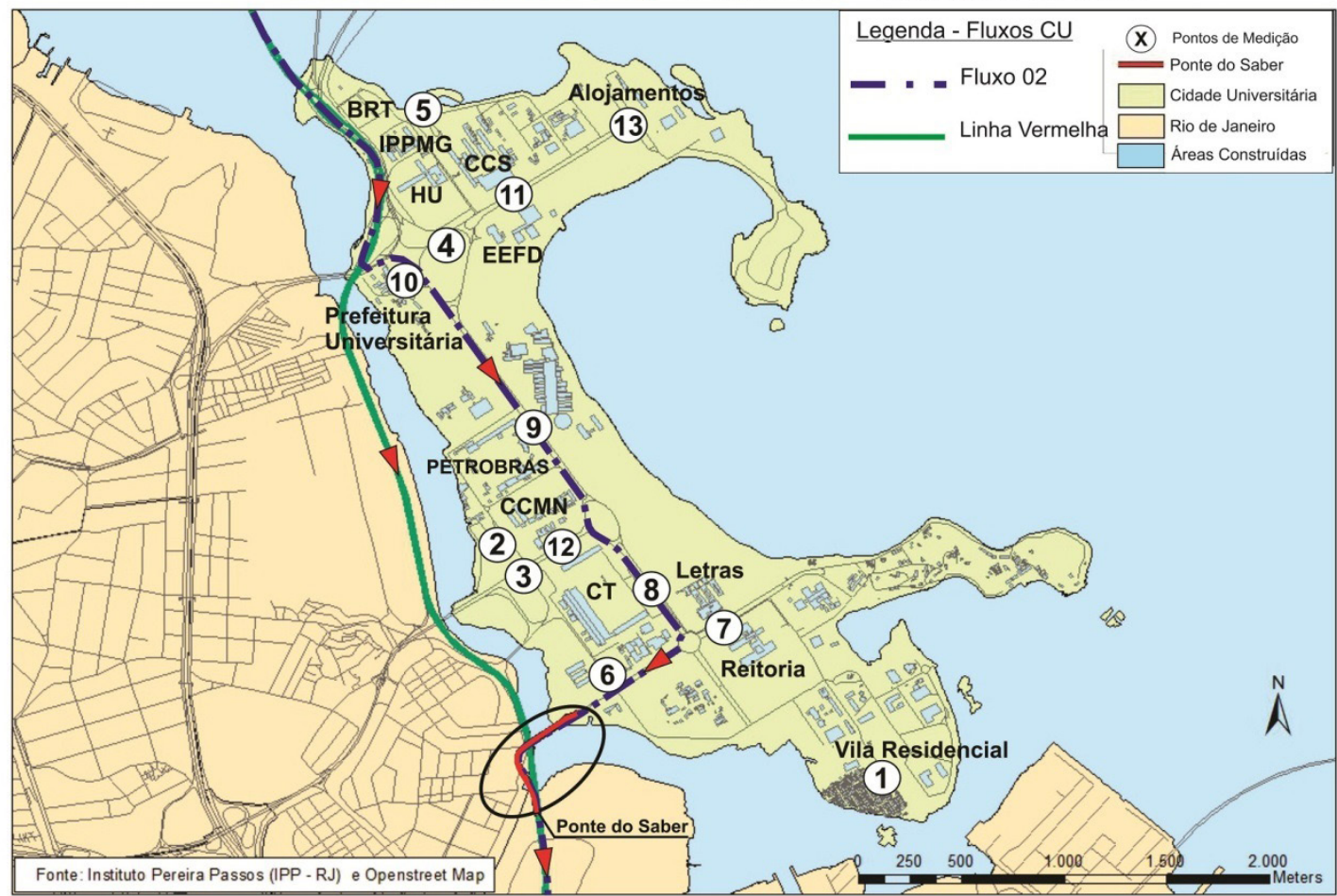

Figura 2 - Fluxo 2 (Sentido Baixada-Centro), Cidade Universitária (RJ)

Fonte: Elaboracão dos autores (2016). 


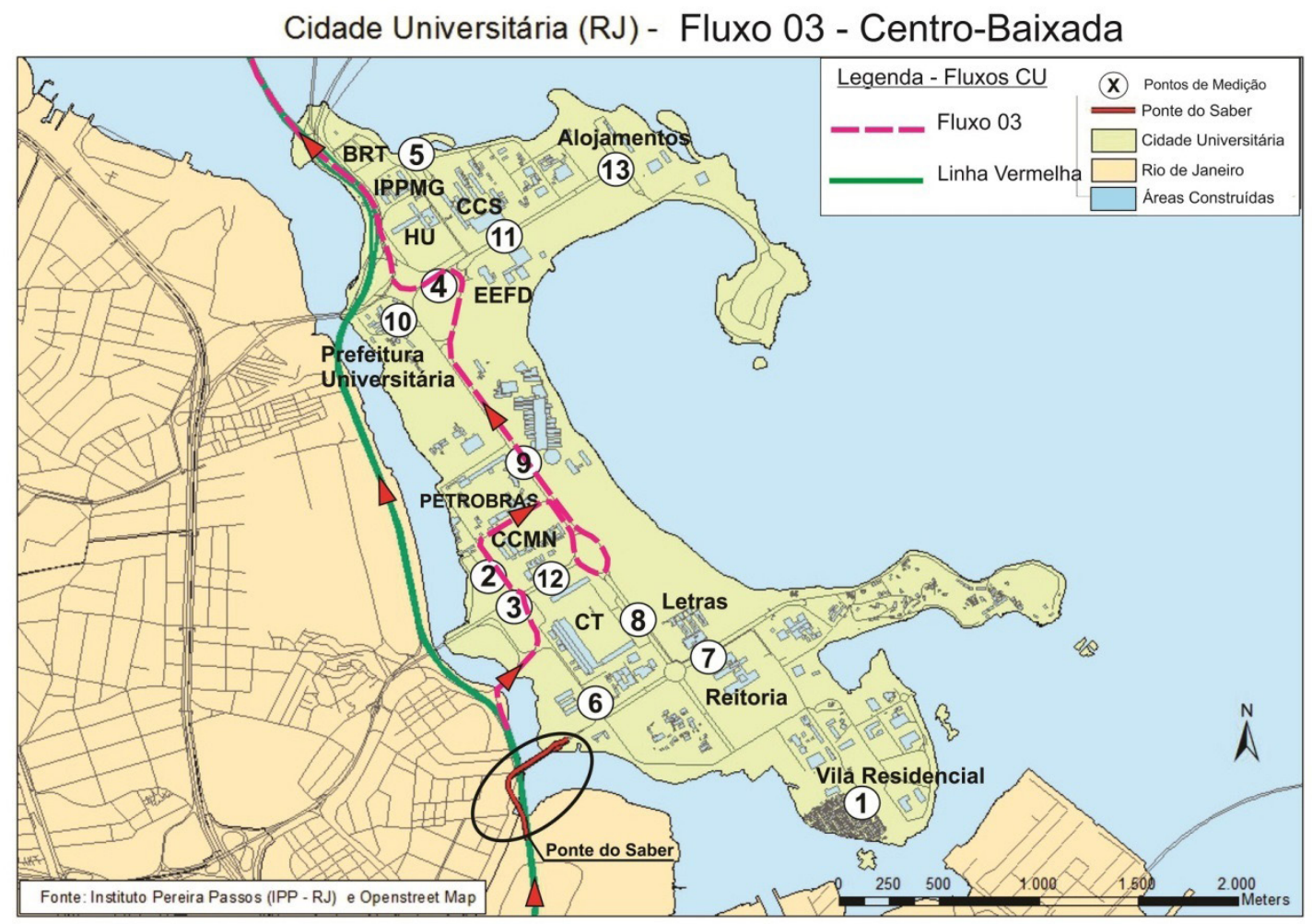

Figura 3 - Fluxo 3 (Sentido Centro-Baixada), Cidade Universitária (RJ)

Fonte: Elaboraç̃õo dos autores (2016).

Baixada-Centro, para os veículos que trafegam pela Linha Vermelha, conforme ilustrado na Figura 2. Devido aos constantes engarrafamentos na Linha Vermelha em horários de pico, esse fluxo ocorre quotidianamente no período da manhã, nas vias da Cidade universitária. Assim, além da poluição sonora produzida pelos veículos e buzinas, ocorre também uma elevação dos níveis de poluição atmosférica.

Na Figura 3, é apresentado o fluxo Centro-Baixada, usado como alternativa à Linha Vermelha pelos automóveis, em geral no período da tarde, devido aos engarrafamentos na Linha Vermelha. Verifica-se, portanto, um aumento no tráfego de veículos na área do Hospital Universitário (HU) e no Instituto de Puericultura e Pediatria Martagão Gesteira (IPPMG), que recebem o fluxo de saída intenso em direção à Linha Vermelha pela Avenida Brigadeiro Trompowski e pelas vias contíguas aos hospitais. Observa-se um conflito de uso do solo, em que tais atividades não deveriam compartilhar o mesmo espaço físico.

No ano de 2014, foi criada a estação do Bus Rapid Transport (BRT — Transporte Rápido por Ônibus), com gerência Municipal e Intermunicipal, com acesso exclusivo a ônibus - ponto 5. Um aspecto positivo dessa intervenção é o incentivo ao uso do transporte coletivo, em detrimento do particular, mesmo verificando-se um aumento do volume tráfego de ônibus no interior da área de estudo. Como os ônibus do BRT não circulam pelas vias internas do Campus, não há um impacto direto desses veículos no ruído da área.

\section{Análise do ruído no campus da UFRJ}

Os desvios de fluxos, como rotas alternativas pelas vias da Cidade Universitária, aumentam a quantidade de veículos e impactam diretamente no conforto acústico. Por esta razão, foi realizada uma análise do ruído no Campus através da elaboração de mapas de ruído.

Os mapas de ruído são úteis para avaliar se os níveis de pressão sonora estão em conformidade com o uso do solo, além de fornecerem informação visual do comportamento acústico de uma área geográfica 
num determinado período de tempo, em função do nível de pressão sonora calculado (Gerges, 2000). Essa análise pode ser feita em micro ou macro escala, sendo importante observar quais aspectos são mais relevantes em função do tipo de variáveis e resultados que se pretende mensurar (Kang, 2007).

Os mapas de ruído foram elaborados através da simulação acústica realizada com a ferramenta CadnaA, que fornece mapas de ruído utilizando modelos matemáticos de emissão e propagação de som, em função das características viárias e de tráfego. Como não existe no Brasil norma específica para o cálculo de propagação, difração, reflexão e outros efeitos, para obtenção dos mapas de ruído, foram utilizas as diretrizes da norma francesa "NMPB-Routes 1996", disponível no software. Dessa forma, são fornecidos valores estatísticos de impacto acústico através de apresentações gráficas em mapas horizontais e também verticais (em fachadas).

A elaboração de mapas de ruído depende do conhecimento prévio sobre dados de tráfego e da tipologia física local, tais como o fluxo de veículos, a composição do tráfego rodoviário e dados sobre as vias. A avaliação da conformidade dos níveis de ruído ao conforto acústico é feita comparando-se os valores calculados, para determinadas áreas ou pontos, com os valores especificados pela norma, conforme o uso do solo. A reação da comunidade local depende das características do ruído e do uso do solo da área em questão. Para este tipo de avaliação, são levadas em consideração as características do ruído, a hora da ocorrência, a duração do ruído e as características da comunidade (Bistafa, 2011).

A simulação acústica realizada no CadnaA demanda a modelagem espacial 3D da área. Esta foi elaborada com o uso da ferramenta AutoCAD, na qual foram demarcados os limites da Ilha, a malha viária, as áreas construídas, as áreas verdes, os estacionamentos e a localização dos receptores (pontos de medição de ruído). Os dados utilizados para elaborar este modelo geométrico foram: fotos aéreas do Google Earht Pro; bases DWG obtidas do site OpenStreetMap; dados levantados in loco, e visualizações do Street View do Google Earth Pro. 0 modelo geométrico consiste da construção de poligonais planas em 3D, que podem representar áreas, vias ou construções, conforme sua associação com os elementos do modelo acústico. As camadas (layers) deste modelo geométrico são importados na extensão dxf para o CadnaA, associandose características acústicas específicas aos objetos de cada camada.
A avaliação do ruído em áreas urbanas foi também objeto de estudo em trabalhos semelhantes (Mardones, 2009; Calixto, 2002; Silva, 2009; Mendonça et al., 2013), dos quais se adaptou a metodologia utilizada para a elaboração do mapa de ruído e a caracterização do cenário acústico.

Foram realizadas contagens de veículos em 13 pontos, situados estrategicamente, nos quais o fluxo de veículos é mais intenso, nos horários de pico, ou onde o uso do solo merece atenção especial, tais como hospital e creche. A contagem de veículos deu-se a partir da análise de vídeos de câmeras fornecidas pelo Centro de Controle e Operação da Cidade Universitária. Os fluxos de veículos das vias determinam seus níveis de potência sonora, que são calculados pela simulação no CadnaA.

Os pontos de medição foram localizados em função dos trajetos descritos na seção acima, das áreas residenciais e das vias de acesso aos principais edifícios da Cidade Universitária. Dessa forma, foi possível conhecer a dinâmica de mobilidade local e auxiliar na proposição de possíveis medidas mitigadoras do ruído para os usuários da Ilha.

Os dados viários (tráfego, tipo de pavimento, velocidade média, fluxos de veículos e proporções entre leves, médios e pesados) e acústicos (fachadas, absorção de vegetações, etc.) coletados nas medições in loco foram inseridos no simulador acústico. 0 mapa de ruído obtido pode ser observado na Figura 4.0 modelo foi validado através da medição dos níveis de pressão sonora nos pontos escolhidos, comparando-os com os resultados obtidos no mapa de ruídos.

As medições de nível de pressão sonora nas vias foram realizadas de acordo com as recomendações da Norma NBR 10.151 (ABNT, 2000). 0 medidor de nível de pressão sonora (sonômetro digital modelo MSL-1354 - Tipo 2) utilizado atende às especificações da NBR 10151 e foi calibrado pelo operador do equipamento, antes e após o conjunto de medições do mesmo evento. 0 equipamento foi configurado para medição de nível de pressão sonora equivalente ponderado em " $\mathrm{A}$ " (Leq) e ajustado para a resposta lenta (slow). 0 efeito de vento sobre o microfone foi prevenido com o uso de protetor apropriado. As medições foram realizadas com o aparelho afastado a 1,2 m do piso, com a utilização de um tripé, a $2 \mathrm{~m}$ ou mais de qualquer superfície refletora. Todas as medições tiveram duração de 20 minutos, com períodos de amostragem de 30 segundos. Os horários escolhidos para medição foram os de picos de tráfego. 
Na Tabela 1, são apresentados os níveis de pressão sonora medidos e simulados. Observa-se que não há diferença significativa entre esses valores, o que valida o modelo acústico e os mapas produzidos.
O mapa apresentado na Figura 4 pode ser considerado representativo do cenário acústico investigado.

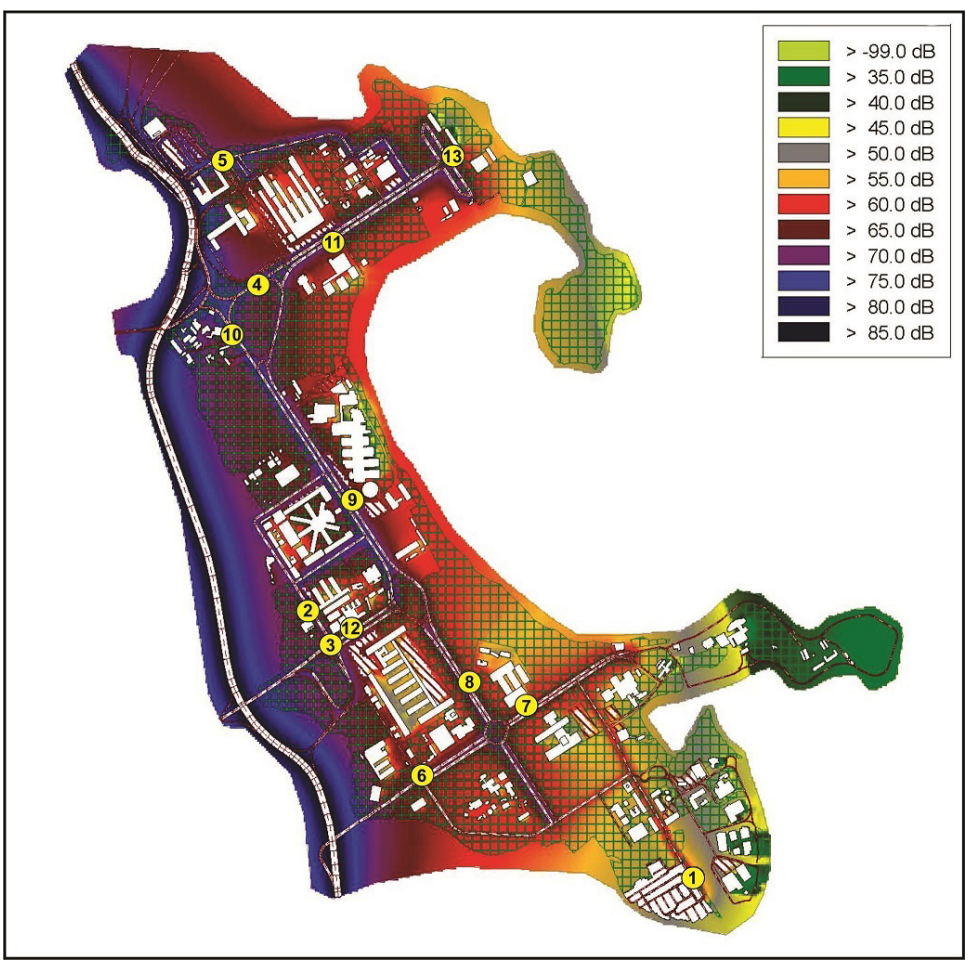

Figura 4 - Mapa de Ruído da Cidade Universitária (RJ)

Fonte: Elaboracãa dos autores (2016).

Tabela 1 - Níveis de ruído aferidos, simulados e adequados em $\mathrm{dB}(\mathrm{A})$

\begin{tabular}{ccccccc}
\hline Ponto & Local & Data & Hora & Medido & Simulado & Adequado \\
\hline 01 & Vila Residencial & $22 / 09 / 15$ & $14 h 57$ & 61 & 61 & 50 \\
02 & Rua Lobo Carneiro & $22 / 09 / 15$ & $15 h 44$ & 68 & 68 & 55 \\
03 & Linha Amarela & $29 / 09 / 15$ & $14 h 41$ & 71 & 70 & 55 \\
04 & Praça Edson Abdala & $29 / 09 / 15$ & $15 h 26$ & 71 & 71 & 55 \\
05 & Terminal Rodovíario & $29 / 09 / 15$ & $16 h 16$ & 68 & 72 & 55 \\
06 & Ponte do Saber & $01 / 10 / 15$ & $09 h 36$ & 66 & 66 & 55 \\
07 & Reitoria & $01 / 10 / 15$ & $11 h 20$ & 60 & 62 & 55 \\
08 & Letras & $01 / 10 / 15$ & $12 h 00$ & 63 & 65 & 55 \\
09 & Petrobras & $01 / 10 / 15$ & $13 h 50$ & 67 & 68 & 60 \\
10 & Prefitura & $01 / 10 / 15$ & $10 h 16$ & 70 & 73 & 60 \\
11 & Centro de Ciências Sociais & $01 / 10 / 15$ & $14 h 33$ & 66 & 69 & 55 \\
12 & Centro de Tecnologia & $01 / 10 / 15$ & $15 h 55$ & 64 & 66 & 55 \\
13 & Alojamento & $01 / 10 / 15$ & $15 h 10$ & 57 & 64 & 50 \\
\hline
\end{tabular}

Fonte: Elaboração dos autores (2016). 


\section{Resultados}

A Organização Mundial da Saúde (OMS) estipula os níveis máximos aceitáveis de exposição a ruído, considerando a susceptibilidade média dos indivíduos. O nível limite de ruído para causar estresse leve com excitação do sistema nervoso e produção de desconforto acústico é de $55 \mathrm{~dB}(\mathrm{~A})$. Segundo a OMS, o nível limite de ruído para causar a perda de concentração e do rendimento em tarefas que exijam capacidade de cálculo é de $60 \mathrm{~dB}(\mathrm{~A})$. Além disso, a exposição contínua é mais nociva do que a interrompida (Brasil, 2006).

No Brasil, os níveis de poluição sonora aceitáveis estão determinados de acordo com o horário e o tipo de zoneamento da área urbana. A Norma NBR 10.151 fixa as condições para avaliação do nível de aceitabilidade do ruído na comunidade, o método para medição do ruído, a aplicação de correções nos níveis de ruído (se necessária) e a comparação dos níveis corrigidos. Segundo a Norma NBR 10.151, que determina o nível de critério de avaliação (NCA) para ambientes externos, em dB (A), a área se enquadra em dois tipos:

- Área estritamente residencial urbana ou de hospitais ou de escolas, onde o NCA é de $50 \mathrm{~dB}(\mathrm{~A})$ para o período diurno e de $45 \mathrm{~dB}(\mathrm{~A})$ para o período noturno;

- Área mista, com vocação comercial e administrativa, onde o NCA é de $60 \mathrm{~dB}(\mathrm{~A})$ para o período diurno e $55 \mathrm{~dB}(\mathrm{~A})$ para o período noturno.

A Norma NBR 10.152 define os valores adequados para o conforto acústico em: Hospitais e Escolas - entre 35 e 55 dB (A); Residências - entre 35 e $50 \mathrm{~dB}(\mathrm{~A})$, e Escritórios - entre 30 e $60 \mathrm{~dB}(\mathrm{~A})$.

A Cidade Universitária pode ser considerada uma zona especial, já que possui áreas hospitalares, acadêmicas, residenciais e de escritórios. Assim, os valores adequados de níveis de ruído para o conforto acústico, nestas condições, devem variar entre 35 e 60 dB (A). Na Figura 4, a cor roxa indica níveis de ruído muito altos, passando pelo vermelho, laranja, amarelo, verde e azul, de forma decrescente. Tanto no mapa de ruído quanto na Tabela 1, observa-se que os níveis de ruído medidos e simulados, em dB (A), são extrapolados em todos os pontos.

Durante a pesquisa, observou-se que o volume de carros é muito superior ao volume de ônibus na maioria dos pontos de medição. Este fenômeno ocorre principalmente nas vias de fluxo mais intenso da Cidade Universitária. Porém, nas vias em que circulam apenas usuários locais, observou-se que o volume de carros é inferior ao volume de ônibus, indicando maior utilização de veículos públicos para o transporte. Isto ocorre nos pontos 7 (Reitoria), 11 (Centro de Ciências da Saúde - CCS / Escola de Educação Física e Desportos - EEFD) e 12 (Centro de Ciências Matemáticas e da Natureza - CCMN / Centro de Tecnologia - CT) (Figura 2).

Esses locais refletem como seria o trafego em todas as vias da Cidade Universitária se não houvesse influência do trafego externo. 0 volume acentuado de carros (muito superior ao número de ônibus) nos demais pontos situados nas vias principais é, portanto, consequência do fluxo externo de veículos. Comprova-se assim a influência negativa do fluxo excedente de veículos provenientes da Linha Vermelha no conforto acústico local.

\section{Medidas mitigatórias}

Diversas opções e combinações de ações são possíveis para atenuar o ruído, seja na sua origem, durante sua propagação ou mesmo no receptor. Além dos aspectos acústicos, também devem ser considerados componentes não acústicos ou psicoacústicos, que possam influenciar positivamente na percepção auditiva do espaço urbano (Yang \& Kang, 2005; Wissmann, 2014).

A percepção humana é multissensorial, sendo rara a percepção de uma situação sonora urbana de forma isolada. Esta é apreendida num contexto integrado, que inclui as informações dos demais órgãos sensoriais, como visão e toque, além da audição. Juntas, essas fontes de informação dão origem a representações mentais multissensoriais do ambiente (Viollon et al., 2002; Bangjun et al., 2003). Um exemplo é o uso de componentes naturais, como vegetação, solução esta eficiente para diminuir o estresse acústico, auxiliando na redução dos níveis de ruído pela consideração de aspectos psicoacústicos, na busca pelo conforto (Carles et al., 1999; Bucur, 2006).

O PD UFRJ-2020 busca romper com o conceito rodoviarista de circulação do projeto original da Cidade Universitária e prevê medidas para melhoria da mobilidade urbana (UFRJ, 2011). Mesmo que indiretamente, algumas destas ações de melhoria 
na mobilidade local auxiliam na redução dos níveis de ruído, tais como:

- Priorização do transporte coletivo de massas em detrimento do automóvel particular;

- Investimento em transporte ativo - pela criação de ciclovias e passeios cobertos para pedestres;

- Mudança da escala monumental e, consequentemente, da velocidade do eixo atual (velocidade média atual de $70 \mathrm{~km} / \mathrm{h}$ ), através de redução das caixas de rua e diâmetros das rótulas;

- Implantação de radares e redutores de velocidade.

Além das medidas de controle de tráfego (velocidade, controle de fluxo, traçado viário) já propostas no PD UFRJ-2020, existem outros meios de contribuir para o conforto acústico ambiental (Bucur, 2006), quais sejam:

- Adoção de placas de trânsito educativas para o comportamento dos motoristas;

- Utilização de materiais acusticamente absorventes (com alta capacidade de absorção das ondas sonoras) nas fachadas das construções;

- Controle de ruído na fonte para o caso do ônibus de transporte interno, exigindo a qualidade acústica dos produtos;

- Estudo prévio sobre o posicionamento das fachadas dos novos edifícios a serem construídos;

- Planejamento e gerenciamento do uso do solo em função dos valores dos níveis de ruído adequados, estipulados por norma-localizando as edificações por zonas de uso do solo (industrial, hospitalar, residencial, comercial, estações de transportes, etc.) e atribuindo limites específicos de ruído sonoro a cada uma;

- Escolha estratégica da distribuição espacial dos equipamentos urbanos, considerando-se o impacto sonoro;

- Exigência de elaboração de projetos de acústica para o licenciamento das novas edificações, definindo diretrizes e normas para o controle de ruído nas novas edificações da Ilha, através de ferramentas de planejamento e gerenciamento urbano, como o Plano Diretor.
Em áreas urbanas com usos diversificados, como é caso da Cidade Universitária da UFRJ, algumas soluções utilizadas para atenuação do ruído são inviáveis, tais como a inserção de grandes e longas barreiras acústicas ou o aumento da distância entre as vias e as edificações. Porém, diversas medidas alternativas, de menor eficiência, são possíveis e podem ser combinadas para atingir níveis de redução de ruído desejáveis.

A reflexão no solo, por exemplo, pode resultar em atenuação ou amplificação do nível sonoro, em função do tipo de material. Dessa forma, podem-se obter reduções de 20 a $30 \mathrm{~dB}(\mathrm{~A})$ ou amplificações de até $6 \mathrm{~dB}(\mathrm{~A})$. A propagação sobre solos acusticamente "duros" (asfalto, terra batida, água, solo inundado, etc.) resulta em amplificações médias de aproximadamente $3 \mathrm{~dB}(\mathrm{~A})$, em relação ao som direto. Já a propagação sobre solos acusticamente "macios" (como vegetação, terra arada ou aerada, ou outros solos fissurados) resulta em significativa atenuação do nível sonoro (Bistafa, 2011). Portanto, a simples substituição do material de superfície das vias por asfalto emborrachado poderia reduzir o ruído de rolagem em 8 a $10 \mathrm{~dB}$ (A) (Morgan \& Watts, 2003). Associada a esta medida, a adoção de barreiras acústicas naturais, com arbustos, por exemplo, também poderia reduzir os níveis de ruído entre 10 e $20 \mathrm{~dB}(\mathrm{~A})$, se as medidas forem utilizadas de forma conjugada (Costa et al., 2013).

O Plano Diretor da UFRJ define algumas áreas do Campus como Centros de Convergência Acadêmicos (CCA) - aqui denominados A, B, C, D, E e F, conforme mostrado na Figura 5. Segundo o zoneamento do PD UFRJ-2020, são zonas para as quais se dirige a maior parte dos usuários da Ilha e, portanto, geram grande fluxo de veículos e convergência de pessoas (UFRJ, 2011). Dessa forma, analisou-se cada CCA, a fim de avaliar a necessidade de medidas que mitigassem o ruído.

Os locais em que os níveis de ruído extrapolaram os valores da Norma foram mapeados e classificados em função de dois fatores: a sensibilidade da área à exposição ao ruído e a previsão de crescimento de área.

A sensibilidade da área foi considerada em função da sua atividade e do nível de pressão sonora máximo permitido pela NBR 10.151, e serve de parâmetro para avaliar o quanto de ruído encontra-se em excesso no CCA. Esse excesso é apresentado na Tabela 2 e é dado pela diferença entre os níveis de ruído medidos e os tolerados pela Norma. 


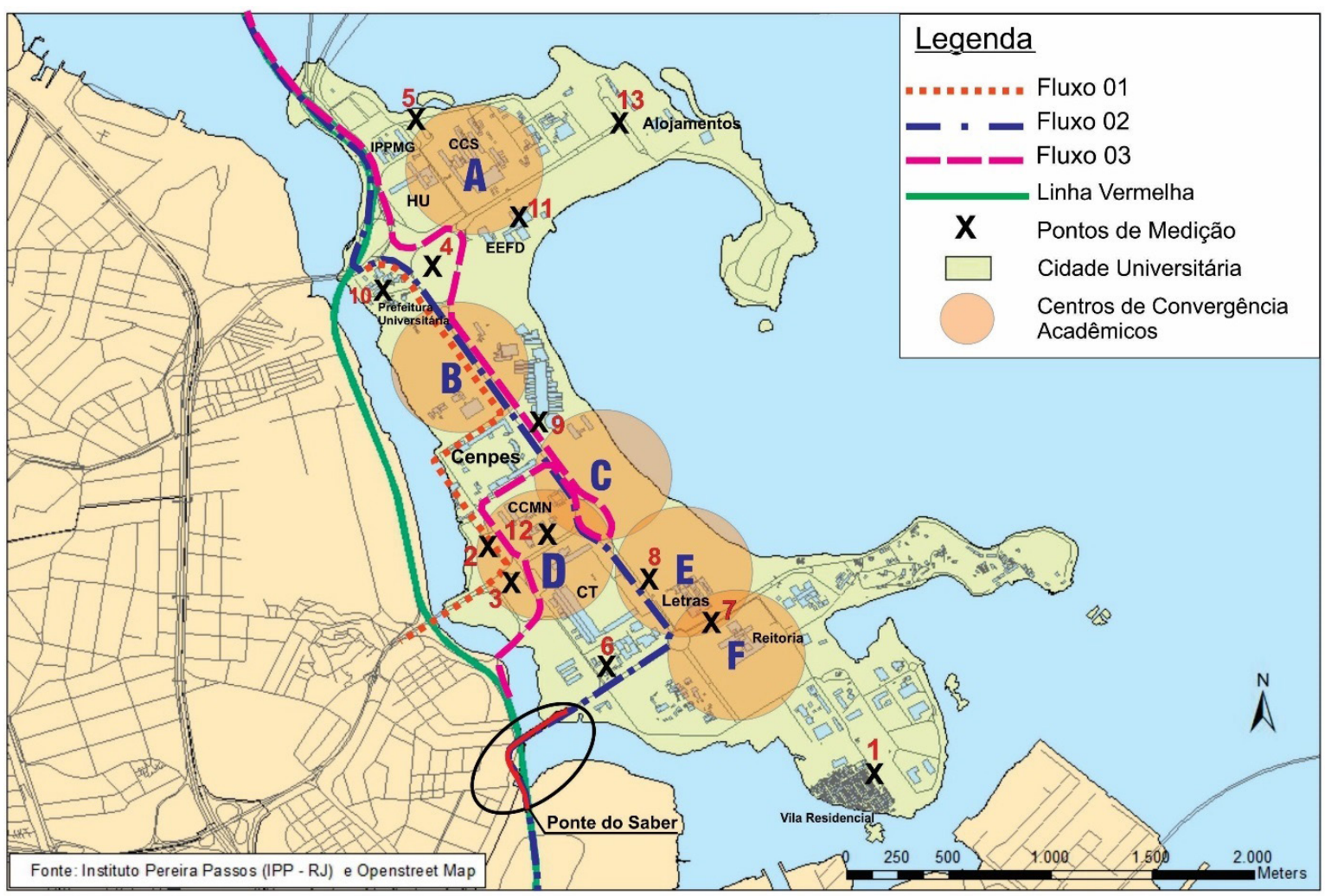

Figura 5 - Mapa de Zoneamento dos Centros de Convergência Acadêmicos (A-F) Fonte: Elaboracạ̃o dos autores (2016).

Tabela 2 - Critério de avaliação do grau de complexidade das intervenções

\begin{tabular}{cccccccc}
\hline CCA & Pontos & Nível Médio & Limite & Excesso & Penalidade & Atenuação & Complexidade \\
\hline A & 4,5 e 11 & 68 & 55 & 13 & 0 & 13 & Moderada \\
B & 10 & 71 & 60 & 11 & 3 & 14 & Moderada \\
C & 9 & 67 & 60 & 7 & 0 & 7 & Baixa \\
D & 2,3 e 12 & 68 & 55 & 13 & 3 & 16 & Alta \\
E & 8 & 63 & 55 & 8 & 0 & 8 & Baixa \\
F & 7 & 60 & 55 & 5 & 0 & 5 & Baixa \\
\hline
\end{tabular}

CCA - Centros de convergência acadêmica. Fonte: Elaboracạ̃o dos autores (2017).

A previsão de crescimento, prevista no PD UFRJ-2020, impacta no cenário futuro, pois mesmo aplicando-se medidas que adequem à situação acústica atual, para valores que atendam à Norma, o aumento do fluxo de pessoas e veículos nos CCAs provocará novamente uma elevação (e extrapolação) dos níveis ideais. Dessa forma, para as áreas em que há previsão de crescimento, deve-se acrescentar um fator de atuação maior do que seria aplicado apenas para corrigir a situação atual.
As soluções acústicas para atenuação do ruído foram, neste trabalho, classificadas como de baixa complexidade, moderada ou complexa, em função do grau de atenuação exigido. Níveis de redução acústica na faixa de $5 \mathrm{a} 8 \mathrm{~dB}$, por exemplo, são obtidos substituindo-se o tipo de pavimento ou pela inserção de barreiras vegetais, sendo, portanto, soluções de baixa complexidade. Níveis de redução na faixa de 10 a $15 \mathrm{~dB}$ exigem soluções combinadas e foram considerados moderados. Quando a atenuação requer valores na 
faixa de 15 a 20 dB ou mais, são necessárias soluções mais complexas, que exigem controle simultâneo do ruído na fonte, na trajetória (durante sua propagação) e até no receptor.

Dessa forma, cada CCA foi classificado em função do grau de complexidade na solução acústica e da previsão de crescimento. 0 grau de complexidade é dado pelo grau de atenuação necessário atualmente, acrescido de uma penalidade estimada de $3 \mathrm{~dB}$ pelo fator de crescimento. Esse valor foi estimado, pois se sabe que, ao duplicar uma quantidade, como, por exemplo o número de pessoas em uma área, há, na escala logarítmica, o acréscimo de $3 \mathrm{~dB}$. 0 crescimento pode ser maior ou menor que esse estimado e não está no escopo deste trabalho.

Este crescimento populacional previsto no PD UFRJ-2020, pela construção de novas edificações, verifica-se mais intensamente nos CCAs B e D, sendo que o primeiro terá uma expansão maior, ainda não iniciada, ao passo que, no CCA D, o crescimento populacional já está em andamento com novas edificações sendo construídas, impactando no ruído acústico atual. Portanto, estes CCAs foram acrescidos da penalidade estimada de $3 \mathrm{~dB}$, como é observado na Tabela 2.

Na Tabela 2, são também apresentados os valores de excesso acústico médio, os valores de penalidade e a atenuação média necessária para cada CCA. Para tanto, foram utilizados os valores médios dos pontos medidos em cada CCA, como forma de obter um panorama geral da área, em vez de atender às necessidades de redução de ruído de pontos específicos.

Com base nos valores finais de redução de ruído (atenuação) da Tabela 2, os CCAs foram classificados pela complexidade das intervenções acústicas, conforme mostrado nesta tabela.

De acordo com a determinação da complexidade de cada CCA, são propostas diferentes medidas mitigadoras da poluição sonora, objetivando reprojetar a situação acústica e auxiliar na elaboração de um plano de redução de ruídos na Cidade Universitária.

Os CCAs A, B e D foram considerados os mais críticos, na análise de ruídos. 0 centro A é uma área hospitalar e, portanto, possui nível de tolerância baixo ao ruído [ $55 \mathrm{~dB}(\mathrm{~A})]$. 0 centro B possui a maior previsão de crescimento, devido ao grande número de construções. 0 centro D já está em fase de expansão, no qual foram construídos novos prédios e há previsão de mais construções. Além disso, o CCA D abriga a maior parte do setor acadêmico da Ilha, em que há a maior densidade de usuários. Adiciona-se a estas características o fato de serem atravessados pelos três fluxos (1 - Linha Amarela; 2 - Baixada-Centro, e 3 - Centro-Baixada), que configuram as rotas alternativas de passagem de veículos.

Observa-se na Tabela 2 que os CCAs C, E e F demandam baixa complexidade. Dessa forma, soluções simples para atenuação dos níveis de ruído na faixa de 5 a $8 \mathrm{~dB}$, tais como substituição da superfície das vias por asfalto emborrachado ou inserção de arbustos em forma de barreiras de vegetação, podem ser aplicadas para a adequação acústica. Estas áreas abrangem os pontos de medição 7, 8 e 9. Nesta zona, encontram-se áreas acadêmicas e áreas concedidas às empresas e centros de pesquisa, além de futuras instalações previstas pelo PD UFRJ-2020.

Os CCAs A e B necessitam de interferências moderadas, segundo a Tabela 2, exigindo soluções combinadas. A troca da superfície das vias por asfalto emborrachado e a adoção de barreiras acústicas naturais em forma de muros de vegetação ou controle de ruído na fonte, para o caso do ônibus de transporte interno, são medidas eficazes para obtenção do grau de atenuação na faixa de 10 a 15 dB. Estes CCAs abrangem os pontos de medição 4, 5, 10 e 11, nos quais estão localizados os terminais rodoviário e do BRT, além das áreas hospitalares.

O CCA D exige interferências de alta complexidade, como observado na Tabela 2. Neste, devem ser conjugados três mecanismos de redução dos níveis de ruído, com controle simultâneo do ruído na fonte, na trajetória e no receptor. 0 controle de ruído na fonte pode ser obtido pela redução de emissão sonora do ônibus de transporte interno, tal como a substituição de toda a frota por ônibus híbridos (Ribeiro \& D’Agosto, 2004). A diferenciação de níveis topográficos nas cabeceiras das vias, a adoção de barreiras acústicas naturais em forma de muros de vegetação e a troca da superfície das vias por asfalto emborrachado são medidas de controle de ruído que podem ser adotadas na trajetória. A utilização de materiais acusticamente absorventes (com alta capacidade de absorção das ondas sonoras) nas fachadas das construções são medidas de controle de ruído no receptor. A combinação destes mecanismos pode atenuar em até $20 \mathrm{~dB}(\mathrm{~A})$ os 
níveis de ruído. Esta zona compreende os pontos de medição 2, 3 e 12, nos quais se encontram áreas acadêmicas e áreas concedidas a centros de pesquisa.

Portanto, na busca de uma Cidade Universitária ambientalmente correta e integrada internamente, como preconiza o PD UFRJ-2020, um plano de redução de ruídos para as zonas com níveis críticos de ruídos seria essencial para o conforto ambiental acústico da Cidade Universitária.

\section{Conclusões}

A análise realizada demonstrou que o Mapa de Ruído é uma ferramenta estratégica de apoio, diagnóstico e planejamento, já que, através da sua observação, podem-se identificar as fontes de ruído predominantes, apontando para a falta de estudos e intervenções sobre o tema, no Brasil. Portanto, o mapa de ruído produzido forneceu orientações relativas às zonas a preservar e/ou a corrigir, do ponto de vista do ruído ambiental, permitindo uma visão global do panorama acústico no território da Cidade Universitária e auxiliando na elaboração de propostas estratégicas de gestão do espaço.

Foram analisados diversos locais na Cidade Universitária e verificou-se que o nível de ruído está acima dos limites indicados pela OMS, em todos os casos. A principal fonte desse excesso é o tráfego local, que é influenciado diretamente pelas intervenções nas vias expressas próximas ao Campus e pelas intervenções internas adotadas pela Prefeitura Universitária.

Ao analisar criticamente o impacto das intervenções viárias que vêm ocorrendo na Cidade Universitária da UFRJ, é importante ressaltar que algumas destas vêm sendo direcionadas pelo Plano Diretor da Universidade, sem que haja uma preocupação com a poluição sonora.

O PD UFRJ-2020 possui um conjunto de "ideias-força", objetivos e princípios que pretendem transformar a Cidade Universitária numa "vitrine" da produção científica (Cidade-Modelo), prevendo humanização de espaços, mobilidade interna, e priorizando transportes coletivos públicos, metro-ferroviário e hidroviário, com o foco no deslocamento dos pedestres, prevendo o conforto ambiental na Ilha, a redução de emissão de poluentes atmosféricos, além da gestão de resíduos. Porém, falha ao não incluir a poluição sonora no seu planejamento, mesmo abordando temas como salubridade, segurança do trabalhador, identificação e controle de riscos, e política ambiental.

Porém, enquanto não for possível criar combinações intermodais que priorizem o transporte metro-ferroviário e hidroviário, melhorando a mobilidade interna através da mudança de concepções rodoviaristas na Cidade Universitária, é importante promover ações para mitigar a poluição sonora. Algumas alterações e medidas mitigadoras da poluição sonora podem integrar a influência do som aos projetos urbanísticos de forma harmoniosa, no intuito de obter um quadro de maior conforto ambiental acústico na Cidade Universitária.

Após a identificação de áreas cujos níveis de ruído ambiente exterior ultrapassem os limites regulamentados, preconiza-se que estas devem ser alvo de planos de redução de ruído. A análise do ruído deve ser articulada com instrumentos de ordenamento do território.

Atualmente, muitos planejadores urbanos brasileiros não consideram a poluição sonora e não estabelecem relação do ruído com a saúde humana ou com o meio ambiente. Este fato torna-se claro ao analisar o PD UFRJ-2020, que falha em não incluir a poluição sonora no seu planejamento, mesmo diante do fato de que o ruído urbano é motivo de desconforto para a maior parte dos habitantes das cidades brasileiras.

É clara a necessidade de conscientização sobre o tema, na busca de melhorias na qualidade de vida dos cidadãos. 0 ruído, além de causar perda auditiva, ocasiona efeitos indiretos sobre a saúde. Apesar de o ruído degradar a qualidade ambiental, não tem sentido considerado pelos planejadores urbanos em suas proposições de desenvolvimento futuro para as cidades.

0 tema exige atenção integrada e multiprofissional, e devem ser apresentadas proposições de ação, de forma ampla e unificada, para a melhoria da qualidade ambiental e da qualidade de vida da população.

Cabe também aos gestores públicos, elaborar políticas mais restritivas, como a análise das licenças ambientais, considerando o impacto sonoro ambiental e as medidas atenuadoras, pois se percebe que é quase inexistente a política de controle do ruído. É preciso que haja maior atenção à qualidade sonora ambiental, com a sua consequente integração nas propostas de políticas públicas. 


\section{Referências}

Associação Brasileira de Normas Técnicas - ABNT. (2000). NBR 10151: acústica: avaliação do ruído em áreas habitadas visando o conforto da comunidade: procedimento. Rio de Janeiro: ABNT.

Bangjun, Z., Lili, S., \& Guoqing, D. (2003). The influence of the visibility of the source on the subjective annoyance due to its noise. Applied Acoustics, 64(12), 1205-1215. http:// dx.doi.org/10.1016/S0003-682X(03)00074-4.

Bistafa, S. R. (2011). Acústica aplicada ao controle do ruído. São Paulo: Blucher.

Brasil. (1998, 13 de fevereiro). Lei no 9.605, de 12 de fevereiro de 1998. Dispõe sobre as sanções penais e administrativas derivadas de condutas e atividades lesivas ao meio ambiente, e dá outras providências. Brasília: Diário Oficial da União. Recuperado em 24 agosto de 2016, de http://www.planalto. gov.br/CCivil_03/leis/L9605.htm

Brasil. (2006). Perda auditiva induzida por ruído (PAIR). Brasília: Editora do Ministério da Saúde.

Bucur, V. (2006). Urban forest acoustics. Champenoux: Springer.

Calixto, A. (2002). O ruído gerado pelo tráfego de veículos em "rodovias-grandes avenidas" situadas dentro do perímetro urbano de Curitiba: analisado sob parâmetros acústicos objetivos e seu impacto ambiental (Dissertação de mestrado). Universidade Federal do Paraná, Curitiba.

Carles, J. L., Barrio, I. L., \& Lucio, J. V. (1999). Sound influence on landscape values. Landscape and Urban Planning, 43(4), 191-200. http://dx.doi.org/10.1016/S0169-2046(98)00112-1.

Costa, C. A., Garavelli, S. L., Silva, E. F. F., Melo, W. C., \& Maroja, A. M. (2013, out.). Barreiras acústicas como medida de mitigação dos ruídos gerados pelo tráfego rodoviário: Setor Noroeste - DF. In Anais do 19º Congresso Brasileiro de Transporte e Trânsito. Brasília: ANTP.

Fundação Oswaldo Cruz - FIOCRUZ. (2015). Campanha alerta para um dos principais problemas ambientais do século XXI: o ruído. Rio de Janeiro: FIOCRUZ. Recuperado em 17 setembro 2015, de https://portal.fiocruz.br/pt-br/content/campanhaalerta-para-um-dos-principais-problemas-ambientais-doseculo-xxi-o-ruido

Gerges, S. N. Y. (2000). Ruído: fundamentos e controle. Florianópolis: NR Editora.

Huang, K., Zhang, J., He, M., \& Zhu, J. (2009). Bi-level programming model of urban traffic network considering noise pollution control. In Proceedings of the International Conference on Transportation Engineering 2009. Reston: American Society of Civil Engineers. http://dx.doi.org/10.1061/41039(345)560.

Kang, J. (2007). Urban sound environment. New York: Taylor \& Francis.

König, A. (2013). Regenerative sustainable development of universities and cities: the role of living laboratories. Cheltenham: Edward Elgar. http://dx.doi.org/10.4337/9781781003640.

Lima, F. R., Santos, M. V. S. M., Almeida, M. L. R., \& Coelho, R. C. S. (2015, nov.). Base de dados elaborada numa plataforma SIG e direcionada para aplicações em Smart Campus. In Anais do II Encontro Nacional de Tecnologia Urbana (ENURB) (pp. 1226-1235). Passo Fundo: UPF Editora.

Mardones, M. D. M. (2009, jul.). Mapeamento dos níveis de ruído em Copacabana, Rio de Janeiro, através de simulação computacional (Dissertação de mestrado). COPPE, Universidade Federal do Rio de Janeiro, Rio de Janeiro.

Mendonça, A. B. D., Suriano, M. T., Souza, L. C. L., \& Viviani, E. (2013). Classes de quadras urbanas determinadas pelos níveis de ruídos. urbe. Revista Brasileira de Gestão Urbana, 5(2), 63-77. http://dx.doi.org/10.7213/urbe.05.002.SE05.

Moreira, N. M., \& Bryan, M. E. (1972). Noise annoyance susceptibility.Journal of Sound and Vibration, 21(4), 449-462. http://dx.doi.org/10.1016/0022-460X(72)90829-2.

Morgan, P. A., \& Watts, G. R. (2003). A novel approach to the acoustic characterisation of porous road surfaces. Applied Acoustics, 64(12), 1171-1186. http://dx.doi.org/10.1016/ S0003-682X(03)00085-9.

Raimbault, M., Lavandier, C., \& Bérengier, M. (2003). Ambient sound assessment of urban environments: field studies in two French cities. Applied Acoustics, 64(12), 1241-1256. http:// dx.doi.org/10.1016/S0003-682X(03)00061-6.

Ribas, A., Schmid, A., \& Ronconi, E. (2010). Topofilia, conforto ambiental e o ruído urbano como risco ambiental: a percepção de moradores dos setores especiais estruturais da cidade de Curitiba. Desenvolvimento e Meio Ambiente, 21, 183-199. http://dx.doi.org/10.5380/dma.v21i0.15599.

Ribeiro, S. K., \& D’Agosto, M. A. (2004). Assessment of hybriddrive bus fuel savings for brazilian urban transit. Transportation Planning and Technology, 27(6), 483-509. http://dx.doi.org /10.1080/0308106042000316376.

Silva, A. S. M. (jun. 2009). Acústica ambiental: análise de ruído urbano (Dissertação de mestrado). Faculdade de Engenharia, Universidade do Porto, Porto. 
Universidade Federal do Rio de Janeiro - UFRJ. (2011). Plano

Diretor da Universidade Federal do Rio de Janeiro 2020: PD UFRJ-2020. Rio de Janeiro: UFRJ.

Viollon, S., Lavandier, C., \& Drake, C. (2002). Influence of visual setting on sound ratings in an urban environment. Applied Acoustics, 63(5), 493-511. http://dx.doi.org/10.1016/ S0003-682X(01)00053-6.

Wissmann, T. (2014). Geographies of urban sound. Farnham: Ashgate.
Yang, W., \& Kang, J. (2005). Acoustic comfort evaluation in urban open public spaces. Applied Acoustics, 66(2), 211-229. http://dx.doi.org/10.1016/j.apacoust.2004.07.011.

Zimmer, K., \& Ellermeier, W. (1999). Psychometric properties of four measures of noise sensitivity: a comparison. Journal of Environmental Psychology, 19(3), 295-302. http://dx.doi. org/10.1006/jevp.1999.0133.

Recebido: Mar. 09, 2017

Aprovado: Jul. 19, 2017 